\begin{tabular}{|c|c|c|c|}
\hline \multirow{2}{*}{ 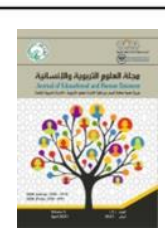 } & \multicolumn{2}{|c|}{$\begin{array}{c}\text { مجلة العلوم التربوية والإنسانية } \\
\text { Journal of Educational and Human Sciences } \\
\text { www.jeahs.com }\end{array}$} & . \\
\hline & Volume (5) April 2021 & العدد (5) أبريل 2021 & \\
\hline
\end{tabular}

\title{
بلاغة الإيجاز في آيات من سورة الأعراف
}

\author{
أ.م. د. خولة صالح صيهود

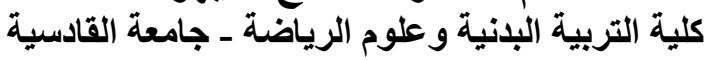 \\ العراق
}

khawla.saihood@qu.edu.iq

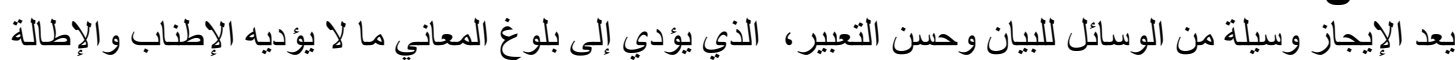

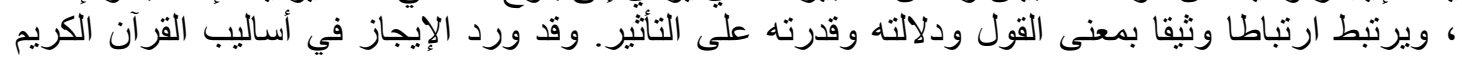

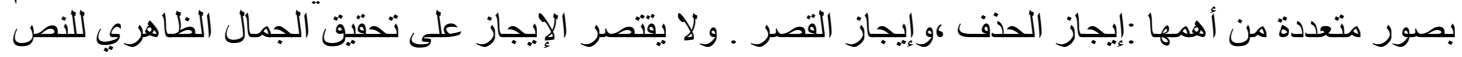

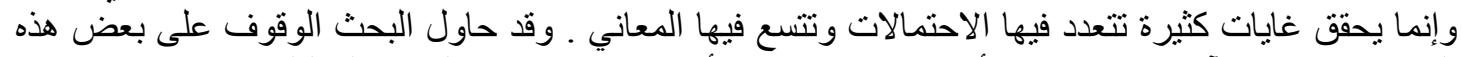

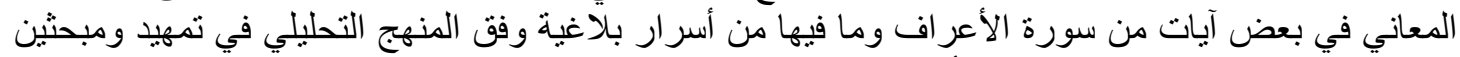

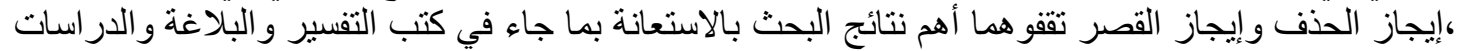
السابقة الني تناولت الإيجاز في القرآن الكريح. الكلمات المفتاحية: بلاغة، الإيجاز، آيات، سورة الأعر اف.
\end{abstract}

\section{Rhetoric of Brevity in verses from Surat Al-A'raf}

\author{
Dr. Khawla Saleh Sihoud \\ College of Physical Education and Sports Sciences - University of Al-Qadisiyah \\ Iraq \\ khawla.saihood@qu.edu.iq
}

\begin{abstract}
Brevity is considered one of the means of articulation and good expression, which leads to reaching the meanings that the excess and prolongation do not do, and it is closely related to the meaning of the saying, its connotations and its ability to influence. The brevity in the methods of the Noble Qur'an has been mentioned in several forms, the most important of which are: brief omission and brevity of minors. Brevity is not limited to achieving the outward beauty of the text, but rather it achieves many goals in which there are multiple possibilities and broad meanings. The research attempted to find out some of these meanings in some of the verses of Surat Al-A'raf and the rhetorical secrets in it according to the analytical method in the introduction and two studies.
\end{abstract}

Keywords: rhetoric, brevity, verses, Surat al-A'raf. 


\section{مجلة العلوم التربوية والإنسانية}

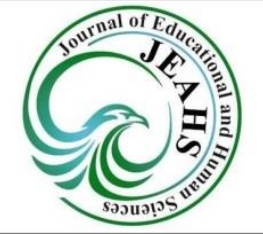

Volume (5) April 2021

العدد (5) أبريل 2021

\section{التمهيد:}

الإيجاز تقليل الكلام من غير إخلال في المعنى و أن تكون المعاني زائدة عن الألفاظ ، مما شكل محور ا هاما

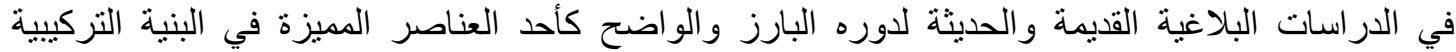
و الوظيفة الجمالية . لاختصار البيان، وطرح فضول الكلام ،وتحصيل المعنى الكثير باللفظ القليل.

وهو نوع من انواع علم البلاغة، و وعصر متميز في التنوع الأسلوبي من حيث البنية التركيبية والفنية و الوظيفة الجمالية ، يولا طاقة إيحائية في مستويات التراكيب ، لما فيه من أسرار بلاغية في اختيار اللفظ المناسب في موضعه المؤثر المؤدي للمعنى بايجاز.

فالإيجاز "هو الجمع للمعاني الكثيرة بالألفاظ القليلة"1، أداء حاجة المعنى، و و" أداء المقصود من الكلام بأقل

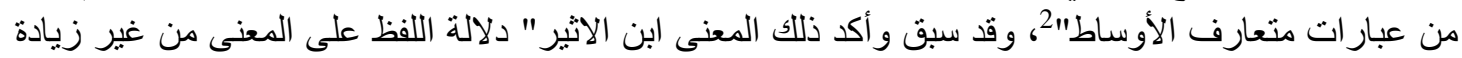

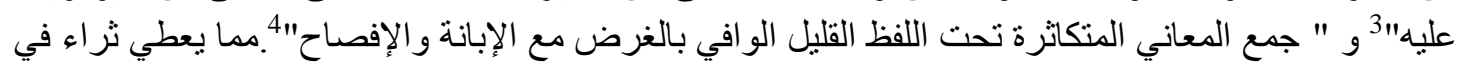

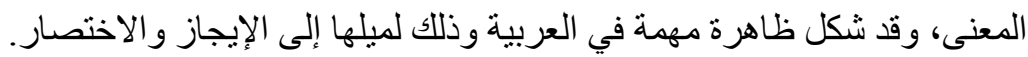

و يعد شكلا من أشكال التحول الاسلوبي يقتضي الدقة والتتبت في التركيب " فما من اسم أو فعل تجده قد

حذف ثم أصيب به موضعه وحذف في الحال ينبخي ان يحذف فيها الا وأنت تجد حذفه هناك الكي أحسن من ذكره"

اتسم الإيجاز في الخطاب القر آني بتنوع الأدوات و الإيحاءات في المفردة مما يؤدي إلى طاقة تعبيرية متنو عة الإنة

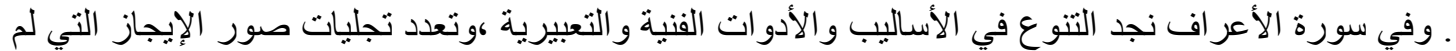

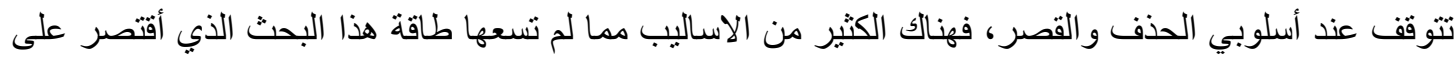

$$
\text { أسلوبين من أكثر أساليب الإيجاز ورودا. }
$$

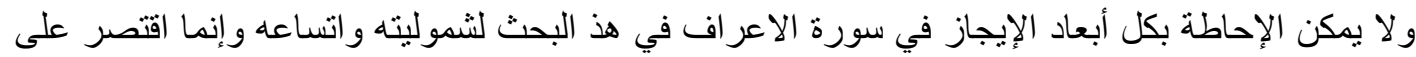

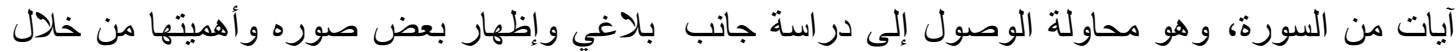

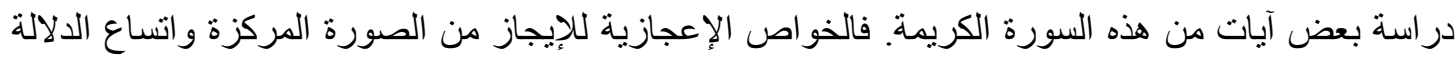

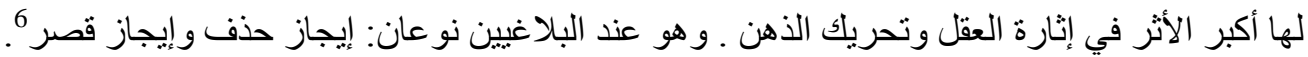

$$
\text { المبحث الأول: ايجاز الحذف }
$$

هو " التعبير عن المعاني الكثيرة في عبارة أقل منها ،بحذف شيء من التركيب مع عدم الإخلال بالمعنى" .7وله

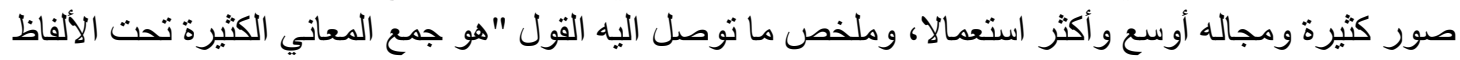

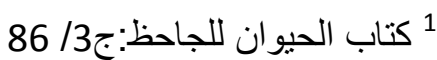

2 مفتاح العلوم للسكاكي:388.

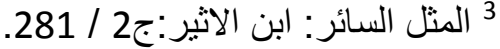

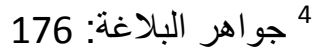

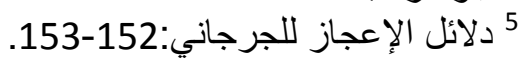

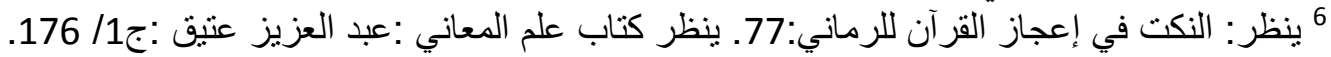
7 المعاني في ضوء أساليب القرآن:315. 


\section{مجلة العلوم التربوية والإنسانية}

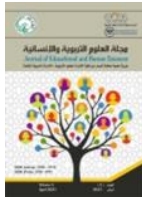

Journal of Educational and Human Sciences www.jeahs.com

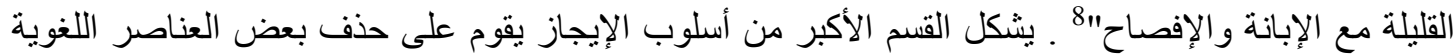

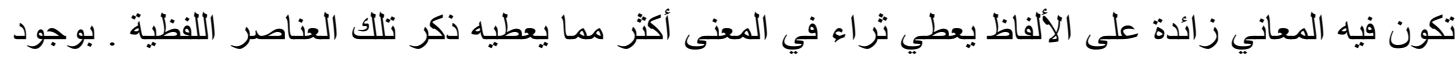

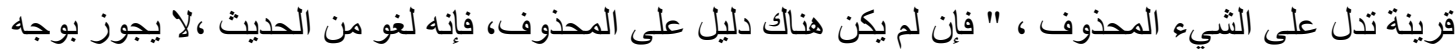

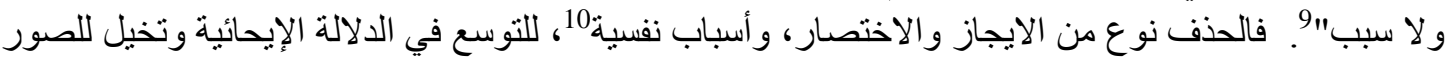
و والمعاني بحسب ما يوحي به النص. فئ.

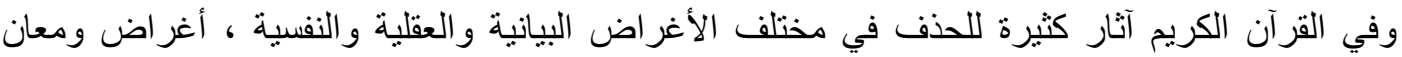

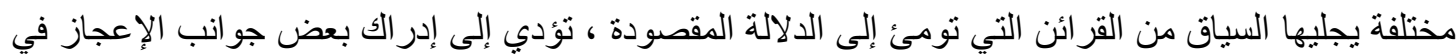
القر آن الكريم.

وفي سورة الأعر اف يأتي الحذف وسيلة للتعبير وطريقة لبيان وتصوير سر عة الحدث وسر عة الإجابة للأمر ،

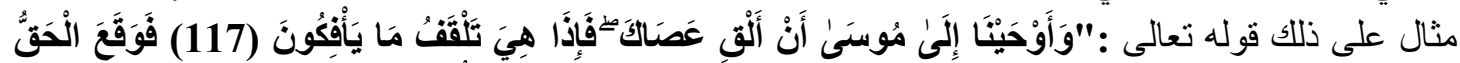

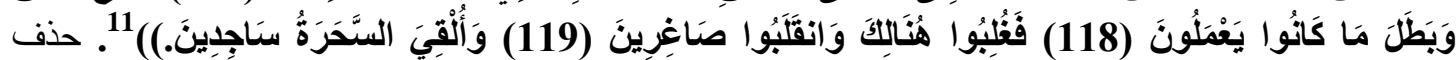

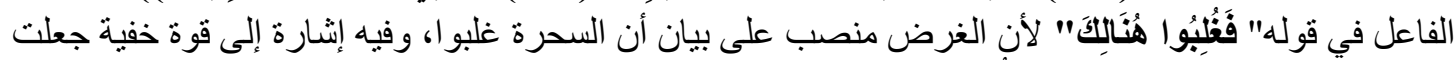

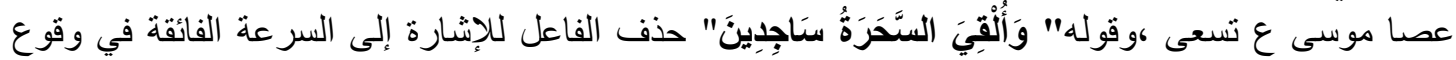

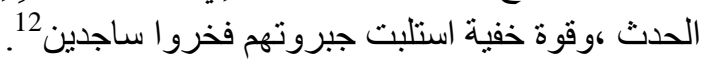

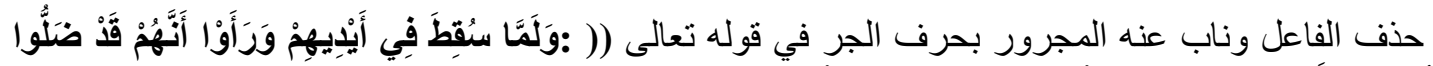

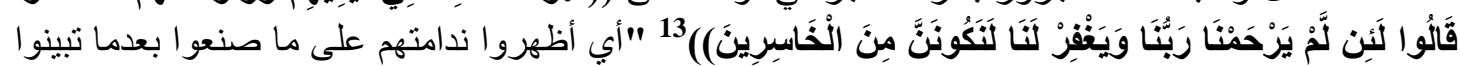

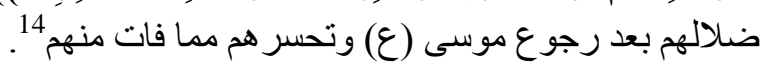

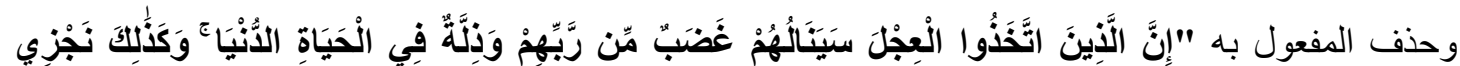

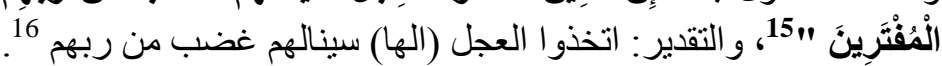

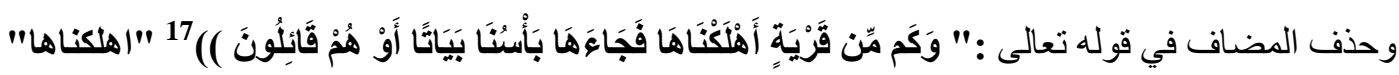

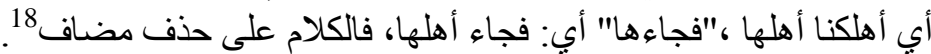

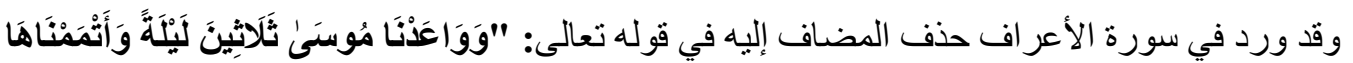
بِعَثْرِ"19 و التقدير :و أتمعناها بعشر (لبال)20. وحذف تمييز عشر لدلالة الكلام عليه.

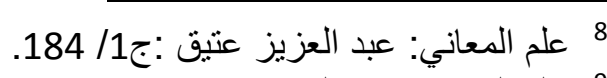

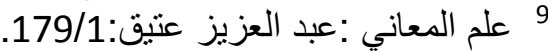

10 بيان اعجاز القرآن(ضمن ثلاث رسائل في إعجاز القر آن)،47،البرهان فئن في علوم القرآن:13/ 122.

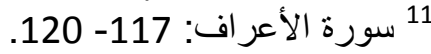

12 ينظر خصائص التر اكيب: 132.

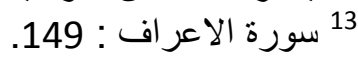

14 ينظر : الميزان في تفسير القر آن:للطباطبائي:ج8: 208.

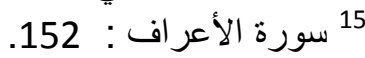

16 ينظر :الاتقان: السيوطي:الاعرة: 151 : 81

17 سورة الأعر اف : 4 : 4.

18 جامع الدروس العربية::مصطفى الغلاييني:478. 


\section{مجلة العلوم التربوية والإنسانية}

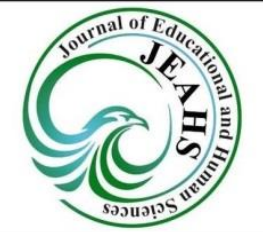

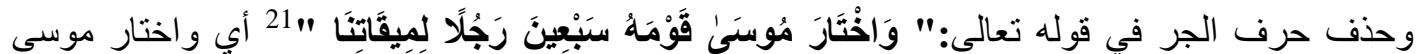

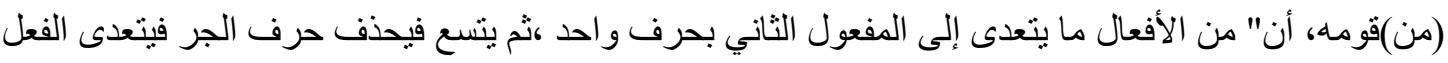

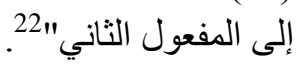

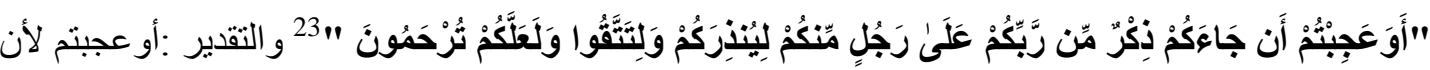
جاءكم

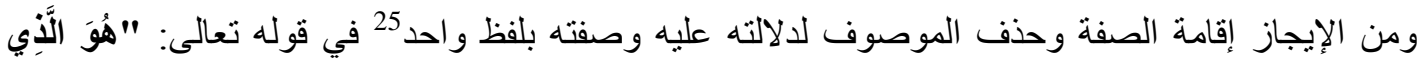

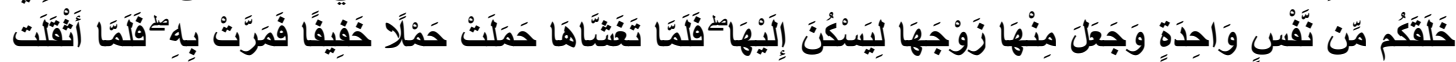

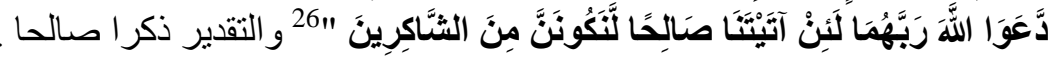

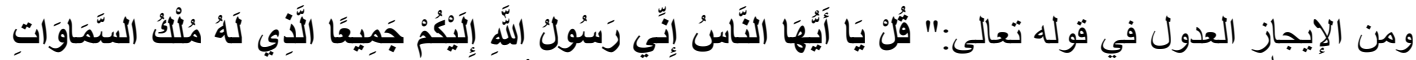

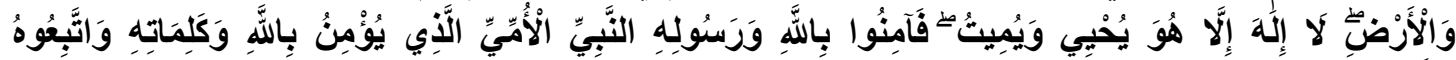

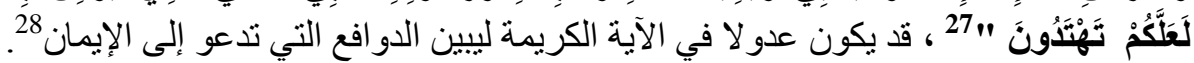

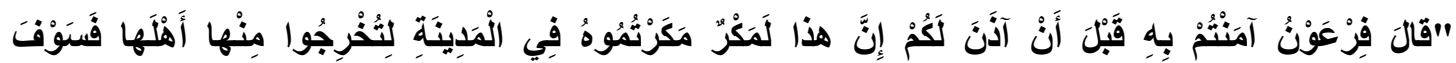

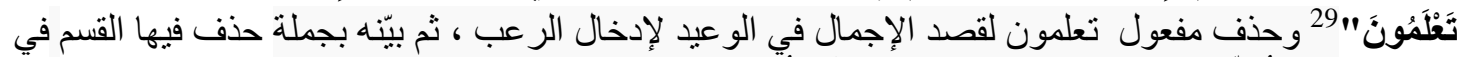

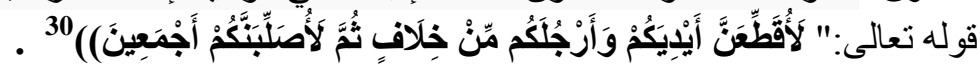

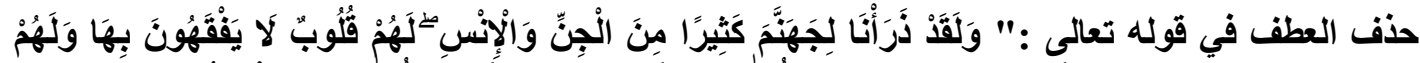

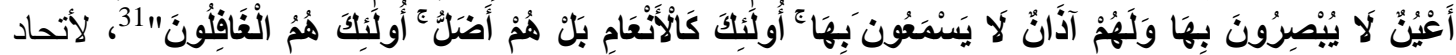

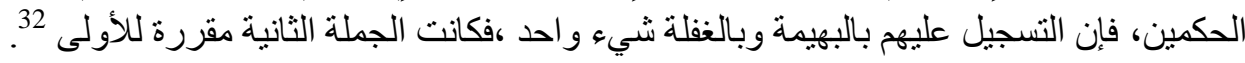

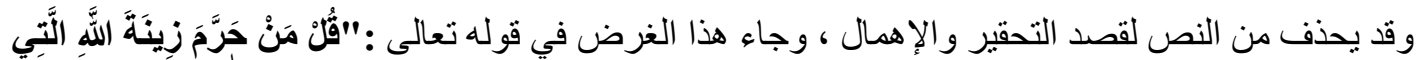

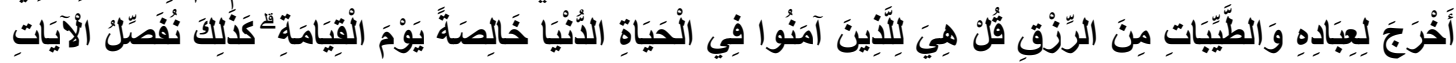

$$
\begin{aligned}
& 19 \\
& 20 \text { ينظر :تفسير :الميز ان:155/8 الاع:196 } \\
& 21 \text { سورة الأعر اف : } 155 .
\end{aligned}
$$

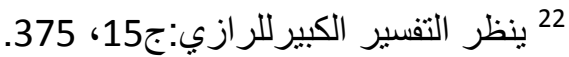

$$
\begin{aligned}
& \text { 23 سورة الأعراف : } 23 \\
& 24 \text { ينظر :جامع الدروس العربية:23 الاع:193/3. } \\
& 25 \text { من أسر ار الإيجاز وصور الإروه في القربة آن الكريم دراسة بلاغية: د. أنشرف حسن محمد:620. } \\
& 26 \text { سورة الأعر اف الف } 189 . \\
& \text { 27 28 سورة الأعراف: } 158 . \\
& 28 \\
& \text { 29 سورة الأعر اف: بلاف: } 123 . \\
& 30 \text { سورة الأعر اف: } 124 . \\
& \text { 31 الفورة الأعر اف: } 179 . \\
& 32 \text { تفسير القرآن الكريم للشيرازي :159/2،ط2،،تحقيق :محمد جعفر شمس الدين ،دار التعارف ،بيروت }
\end{aligned}
$$




\section{مجلة العلوم التربوية والإنسانية}

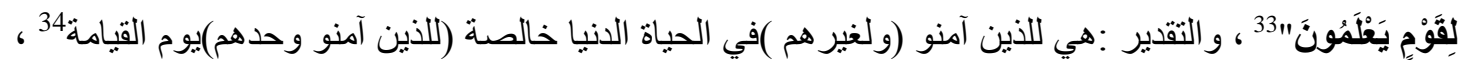

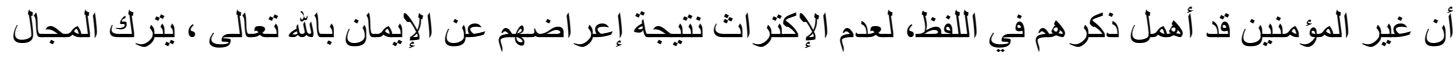

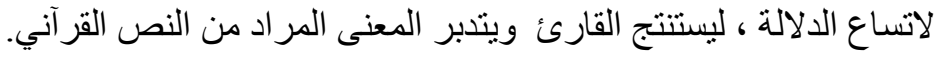

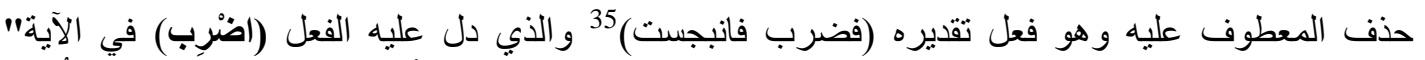

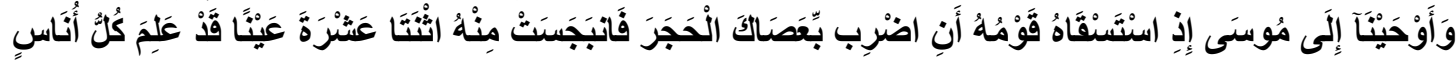

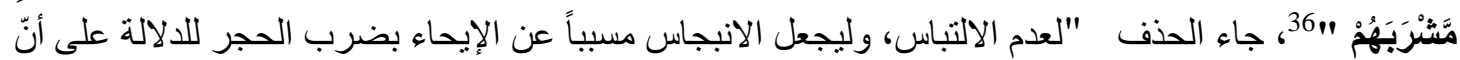

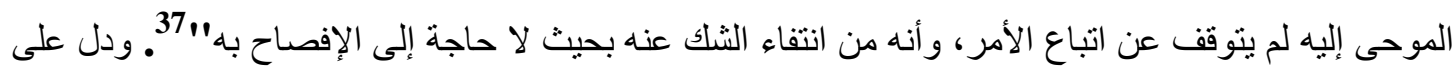

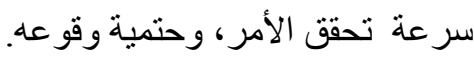

\section{المبحث الثاني: إيجاز القصر}

يعد القصر من الإيجاز وركنا من أركان البلاغة ،يؤدي الى معاني متنوعة كالاختصاص و التأكيد ،و المدحح

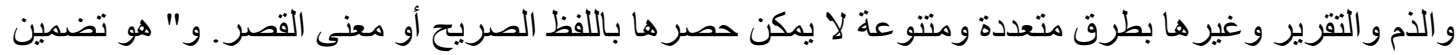

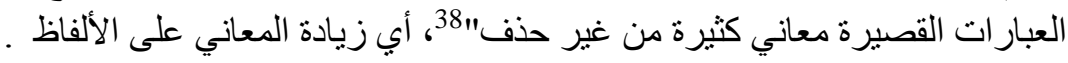

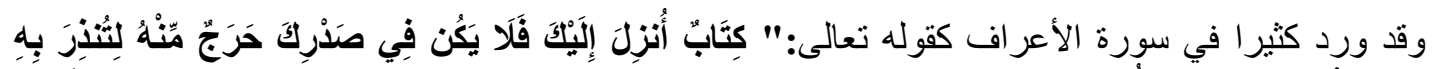

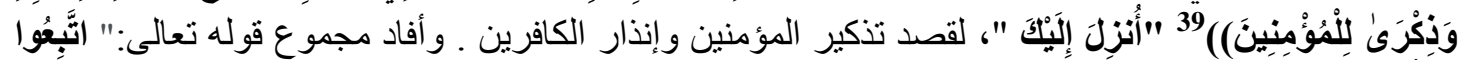

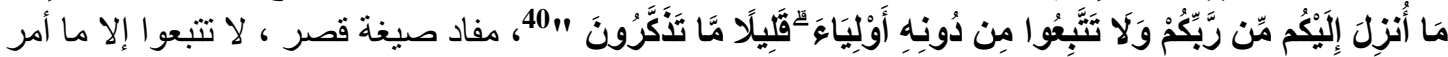

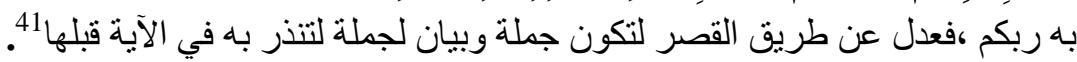

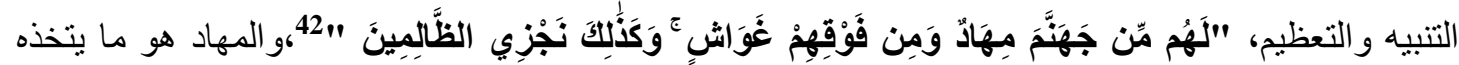
الإنسان فر اثا ووطاء، فإن النار هي فر اثهم و غطاءهم يغشاهم العذاب، فقد جاء بلفظة مهاد لتحكي أنو اع العذاب

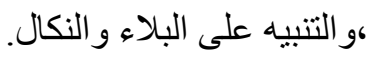

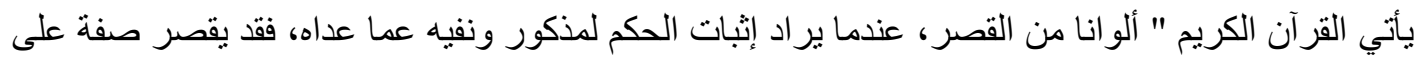

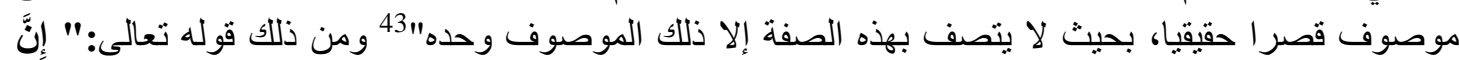

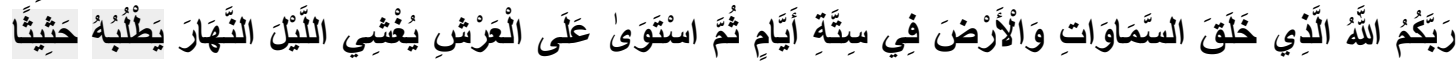

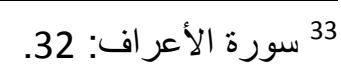

34 ينظر: تفسير التحرير و التنوير :ج8: 32 35 ينظر: البحر المحيط :34/ 390. 36 سورة الأعراف: 160.

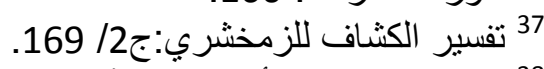

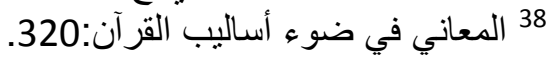
39 سورة الأعر اف: 2. سورة الأعر اف: 3.

41 ينظر: تفسير الاعراف: 30

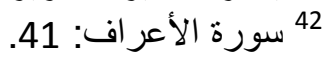
43 من بلاغة القرآن : أحمد أحمد بدوي:121. 


\section{مجلة العلوم التربوية والإنسانية}

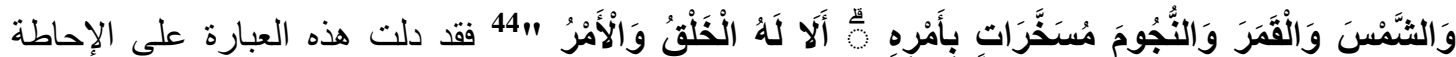

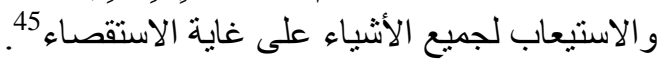

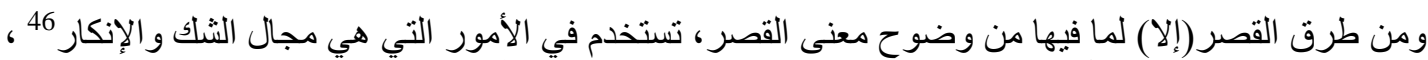

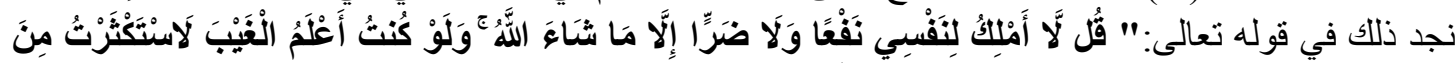

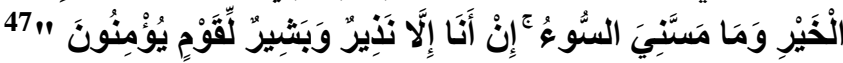

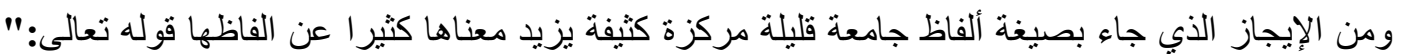

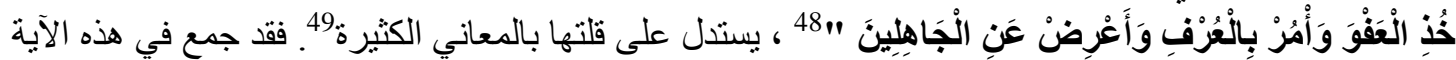

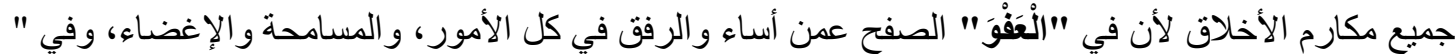

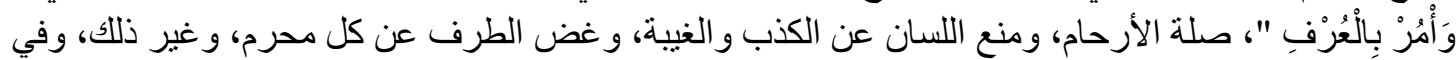

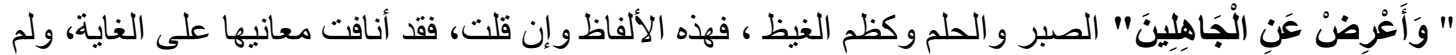
تقف على حد ونهاية.

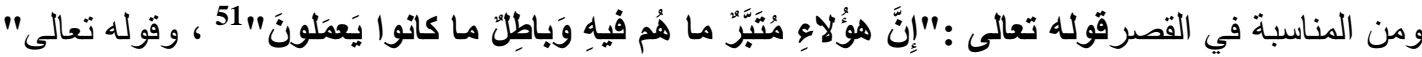

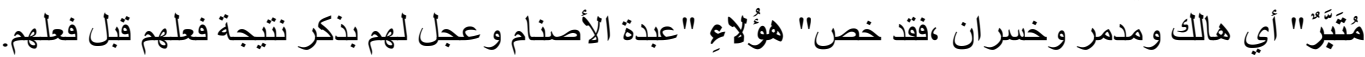

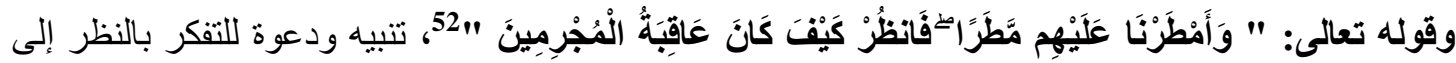

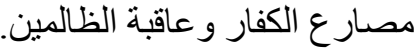

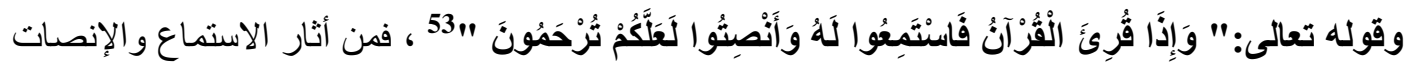

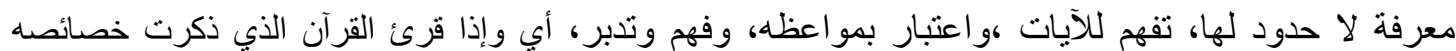
ومز اياه عليكم فاستمعو اله بتنبر وخشوع، ... فقيه التنبيه و التحفيز.

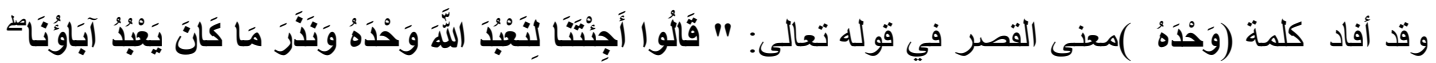

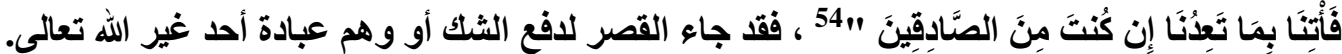
الإيحاءات اللفظية تحيل إلى أبعاد دلالية أوسع لوجود طاقة كامنة في مفردات النظم القر آني مما يعد سياقات أخرى تندر ضمن مفهوم الإيجاز.

$$
44 \text { سورة الأعر اف: } 54 .
$$

45 ينظر : علم المعاني : عبد العزيز عتيق :ج1: 177، المعاني في ضوء اساليب القرآن::320_321. 46 من بلاغة القرآن :أحمد أحمد بدوي:122.

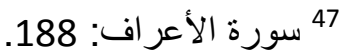
(48 سورة الأعر اف: 199. 49 أساليب بلاغية: أحمد مطلوب:198 50 المعاني في ضوالب بلاغية أساليب القرآن:32

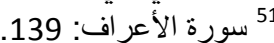

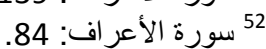
(53 سورة الأعر اف: 204.

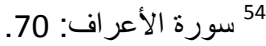




\section{مجلة العلوم التربوية والإنسانية}

Journal of Educational and Human Sciences www.jeahs.com

ـ الإيجاز في آيات من سورة الأعراف جمع معاني كثيرة وأدى إلى تحصيل المعنى بألفاظ قليلة مع الإبانة و الإفصاح بنو عيه إيجاز الحذف و إيجاز القصر.

ـ ـ الإيجاز بنوعي الحذف و القصر جعل الصياغة أكثر ثر اء في المعنى من التركيبات اللغوية الكاملة. ـ ينتج عن الإيجاز أثار نفسية ومعنوية كثيرة لها أكبر الاثر في المتلقي، وليس لغرض الاختصار فقط.. ـ الإيجاز بالحذف يكون بقرينة تعين على معرفة المحذوف . - يرد كثير ا في الإيجاز الحذف بكلمة، وقد يأتي الإيجاز بحرف. ـ ايجاز القصر تضمن عبارات قصبرة من غير حذف.

1. أساليب بلاغية الفصاحة ـالبلاغة_المعاني :أحمد مطلوب ،وكالة المباني المطبو عات، الكويت،1980. 2.

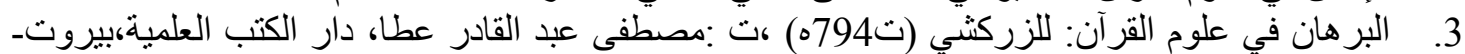

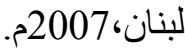

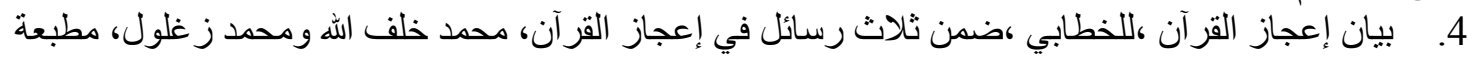

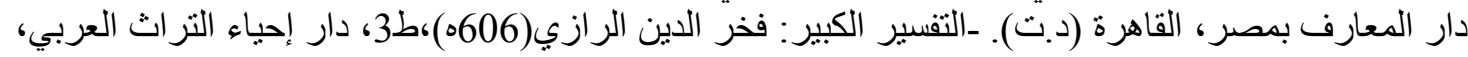

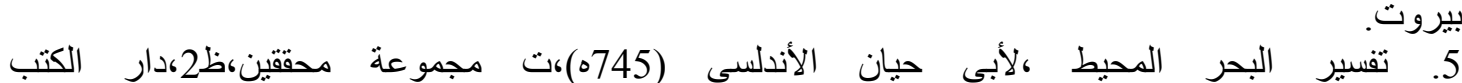
6. تفسير التحرير و التنوير لابن عاثور(1393ه )،الدار التونسية للنشر-تونس،1984.تفسير القرآن الكريم

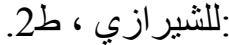
7. جامع الدروس العربية: مصطفى الغلاييني ، تنقيح :سالم شمس الدين ، ط1، دار الكر خ للطباعة والنشر.

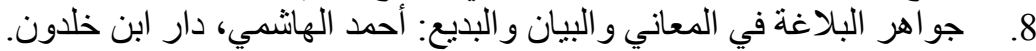

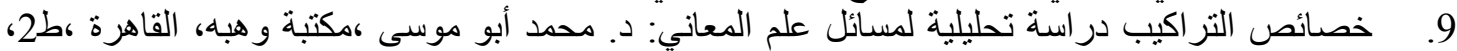
1980م.

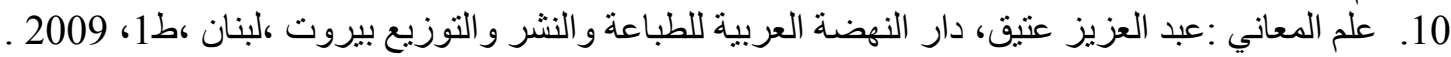

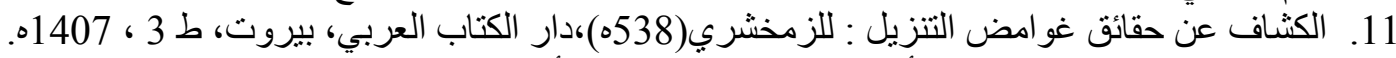

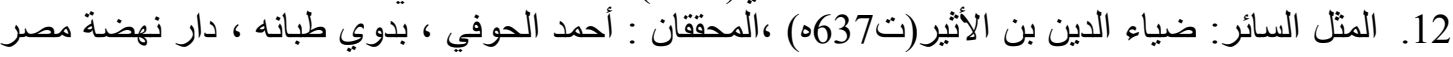

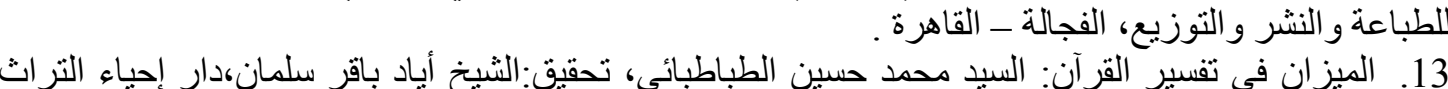

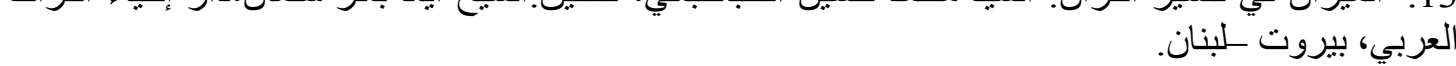
14. مفتاح العلوم : للسكاكي (ت 626ه) ، تحقيق: نعيم زرزور، دار الكتب ،العلمية ،بيروت-لبنان ، ط2

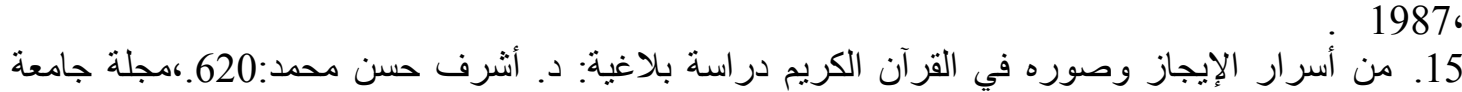

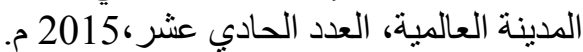
16. من بلاغة القرآن : أحمد أُحمد بدوي ،نهضية مصر للطباعة و النشر و التوزيع،2005م. 


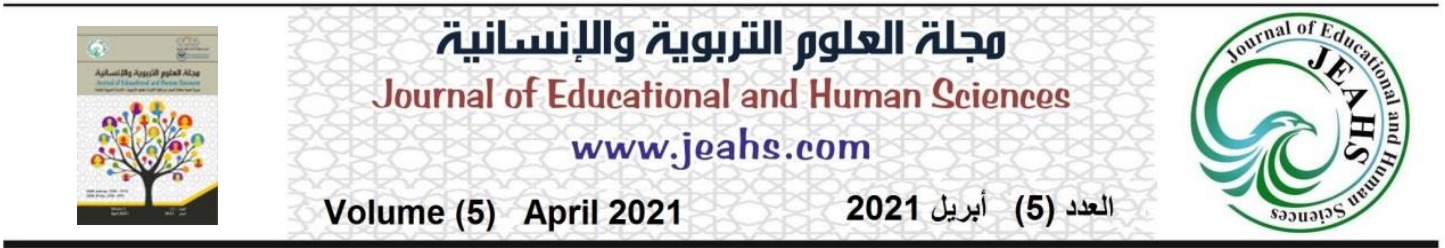

\section{References}

1. Rhetorical Methods of Eloquence - Rhetoric - Meanings: Ahmad Matlab, Publications Agency, Kuwait, 1980.

2. Perfection in the Sciences of the Qur'an, by al-Suyuti, Mustafa al-Babi al-Halabi, Egypt „, 4th Edition, 1978 AD.

3. Evidence in the Sciences of the Qur'an: Al-Zarkashi (d.794 A.H.), T.: Mustafa Abdel-Qader Atta, Dar Al-Kotob Al-Alami, Beirut-Lebanon, 2007 AD.

4. Explanation of the Qur'an's Miracles, for Al-Khattabi, in the three treatises on the Miracles of the Qur'an, Muhammad Khalaf Allah and Muhammad Zaghloul, Dar Al Ma'arif Press, Cairo (d. - The great interpretation: Fakhr al-Din al-Razi (606 AH), 3rd Edition, House of Revival of the Arab Heritage, Beirut.

5. Interpretation of the Ocean Al-Bahr, by Abu Hayyan Al-Andalusi (745 A.H.), a group of investigators, V2, Dar Al-Kotob Al-Alami, Beirut, Lebanon, 2007 AD.

6. Interpretation of Tahrir and Enlightenment by Ibn Ashour (1393 AH), Tunisian Publishing House - Tunis, 1984.

7. Interpretation of the Noble Qur'an: by Shirazi, i 2.

8. The Collector of Arabic Lessons: Mustafa Al-Ghalayini, Revision by: Salem Shams Al-Din, 1st Edition, Dar Al-Karkh for Printing and Publishing.

9. Jawaher Al-Balaghah on Meanings, Bayan and Badi ': Ahmad Al-Hashemi, Dar Ibn Khaldun.

10. Properties of structures An analytical study of semantics issues: Dr. Muhammad Abu Musa, Wahba Library, Cairo, 2nd Edition, 1980 AD.

11. The Science of Meanings: Abdulaziz Ateeq, Dar Al-Nahda Al-Arabiya for Printing, Publishing and Distribution, Beirut, Lebanon, 1st Edition, 2009.

12. Revealing the facts of the mysteries of the revelation: by Al-Zamakhshari (538 AH), Dar Al-Kitab Al-Arabi, Beirut, 3rd ed.

13. The preceding example: Diaa Al-Din Ibn Al-Atheer (d.637 AH), the investigators: Ahmed Al-Hofi, Badawi Tabana, Nahdet Misr House for Printing, Publishing and Distribution, Faggala - Cairo.

14. Al-Mizan in the Interpretation of the Qur'an: Mr. Muhammad Husayn alTabataba'i, edited by: Sheikh Ayad Baqir Salman, House of Revival of Arab Heritage, Beirut-Lebanon.

15. Miftah Al-Uloom: Laskaki (d.626 AH), edited by: Na`im Zarzour, Dar Al-Kutub, Al-Alamiah, Beirut-Lebanon, 2nd Edition, 1987.

16. Among the secrets of brevity and its images in the Noble Qur'an a rhetorical study: Dr. Ashraf Hassan Muhammad: 620., Al-Madinah International University Journal, 11th Issue, 2015 AD.

17. From the rhetoric of the Qur'an: Ahmad Ahmad Badawi, Nahdet Misr for Printing, Publishing and Distribution, 2005 AD. 